\title{
Synthesis and Characterization of $\mathrm{SnO}_{2}$ Flower-Shaped by Hydrothermal Route for Formaldehyde Sensing Properties
}

\author{
Abeer Alhadi' ${ }^{1}$, Shuyi Ma1 $^{*}$, Shitu Pei ${ }^{1}$, Tingting Yang1, Pengdou Yun', Qianqian Zhang1, \\ Hamouda Adam Hamouda2,3, Li Wang1, Omer Almamoun4, Altayeb Alshiply5, Pengfei Cao1, \\ Manahil H. Balal ${ }^{6,7}$, Khalid Ahmed Abbakar ${ }^{7,8}$
}

\author{
${ }^{1}$ Key Laboratory of Atomic and Molecular Physics \& Functional Materials of Gansu Province, College of Physics and Electronic \\ Engineering, Northwest Normal University, Lanzhou, China \\ ${ }^{2}$ College of Chemistry and Chemical Engineering, Northwest Normal University, Lanzhou, China \\ ${ }^{3}$ Department of Chemistry, Faculty of Science, University of Kordofan, El Obeid, Sudan \\ ${ }^{4}$ Faculty of Petroleum and Hydrology Engineering, West Kordofan, Peace University, Almugled, Sudan \\ ${ }^{5}$ Department of Physics, Faculty of Education, University of Khartoum, Khartoum, Sudan \\ ${ }^{6}$ Physics Department, Faculty of Science and Art, Al Baha University, Gilwah, KSA \\ ${ }^{7}$ Department of Mathematics and Physics, Faculty of Education, University of Gadarif, Gadarif, Sudan \\ ${ }^{8}$ College of Mathematics and Statistics, Northwest Normal University, Lanzhou, China
}

Email: *abeeralhadi18@hotmail.com

How to cite this paper: Alhadi, A., Ma, S.Y., Pei, S.T., Yang, T.T., Yun, P.D., Zhang, Q.Q., Hamouda, H.A., Wang, L., Almamoun, O., Alshiply, A., Cao, P.F., Balal, M.H. and Abbakar, K.A. (2021) Synthesis and Characterization of $\mathrm{SnO}_{2}$ Flower-Shaped by Hydrothermal Route for Formaldehyde Sensing Properties. Advances in Materials Physics and Chemistry, 11, 67-77.

https://doi.org/10.4236/ampc.2021.114007

Received: March 11, 2021

Accepted: April 3, 2021

Published: April 6, 2021

Copyright $\odot 2021$ by author(s) and Scientific Research Publishing Inc. This work is licensed under the Creative Commons Attribution International License (CC BY 4.0).

http://creativecommons.org/licenses/by/4.0/

\begin{abstract}
In this work, we've made $\mathrm{SnO}_{2}$ flower formed with the aid of using easy test steps, and without cost, which is the hydrothermal approach and without a template. We have used a variety of techniques to characterize $\mathrm{SnO}_{2}$ flowershaped by (SEM, TEM, XRD, BET and XPS) instruments. Confirmatory tests carried out have proven that the surface of the tetragonal structure of $\mathrm{SnO}_{2}$ has a rough surface which makes it excellent for its gas-sensing properties. The gas detection test of $\mathrm{SnO}_{2}$ flower-shaped proved that it possesses the selectivity of formaldehyde gas (about 30), the optimum operating temperature of the sensor is $220^{\circ} \mathrm{C}$, and also the sensor has a high response time and recovery time is ( $5 \mathrm{~s}$ and $22 \mathrm{~s}$ ) to $100 \mathrm{ppm}$, respectively. Particularly, the sensor has an obvious response value (2) when exposed to $5 \mathrm{ppm}$ formaldehyde. As well, the mechanism of gas-sensing was also discussed.
\end{abstract}

\section{Keywords}

$\mathrm{SnO}_{2}$ Flower-Shaped, Hydrothermal Method, Formaldehyde, Semiconductor, Gas Sensor

\section{Introduction}

VOCs (Volatile organic compounds) are responsible for the odor, scents, and 
perfumes as well as pollutants. Some VOCs are very serious matters to human health and cause harm to the environment. Most VOCs are flammable, explosive, and toxic, and are mainly found in the gaseous phase, so they need to be detected to preserve the health of the peoples [1] [2]. Formaldehyde is a form of a volatile organic compound, so it must be disclosed that it is toxic and odorless, and is considered a cause of environmental pollution [3] [4], Formaldehyde is fatal if exposed for short periods of time and exposure to it for a long period's cause's difficulty breathing, as it is a carcinogen [5], It is necessary to find a high-performance sensor to detect formaldehyde gas because it is already internationally classified by the IARC (International Agency for Research on Cancer) [6]. The MOS (metal oxide semiconductor) such as $\mathrm{WO}_{3}, \mathrm{ZnO}, \mathrm{SnO}_{2}, \mathrm{NiO}$, $\mathrm{Cu}_{2} \mathrm{O}$, and $\mathrm{In}_{2} \mathrm{O}_{3}$ have been used due to their stable properties in chemical transport, so it has been widely used for the detection of different kinds of volatile organic compounds [7]. In detail, $\mathrm{SnO}_{2}$ (n-type) has the best MOS because it has many advantages such as low cost, good stability, ultra-high sensitiveness, also has excellent performance of gas sensors. The flower-like structure can cause vast concern owing to its tailored structure and high surface area, which is applicable for gas adsorption and desorption [8] [9] [10].

Gas sensors based on $\mathrm{SnO}_{2}$ materials were developed by many researchers, D. P. Xue, Y. W, et al. synthesis of $\mathrm{SnO}_{2}$ sensor to methane by an impregnation route [11], Q. W, P. S et al. discussed $\mathrm{SnO}_{2}$ sensor to find out formaldehyde via hydrothermal technique [12], According to the previous researches, detecting gas sensors to the pure $\mathrm{SnO}_{2}$ didn't Achieve Gas sensor detection requirements [13] [14] [15] [16], but in our work pure $\mathrm{SnO}_{2}$ has good sensing materials for gas sensors detecting. In gas-detection $\mathrm{SnO}_{2}$ sensors have been utilized closely none less, they are usually used at high operating temperatures (above $300^{\circ} \mathrm{C}$ ). Thus, it is important to create and develop $\mathrm{SnO}_{2}$ sensors for low-temperature [17].

In this subject, the hydrothermal technique is used to prepare $\mathrm{SnO}_{2}$ flowershaped. Various analysis techniques were used to test the $\mathrm{SnO}_{2}$ sample. Performance of gas sensing has been discussed systematically, like a response to diverse concentrations, response to various gases and response/recovery time. Optimum operating temperature, and stability, Likewise, we studied the gas sensor mechanism. Consequently, the $\mathrm{SnO}_{2}$ material could be a good new kind of formaldehyde gas sensor in later years.

\section{Experimental}

In this experiment, all chemicals were used without any further purification, the steps of hydrothermal method are as follows; $0.4 \mathrm{~g}$ Tin (II) Chloride dehydrates, 2.5 g Sodium Citrate dehydrate, and $0.3 \mathrm{~g}$ Polyvinylpyrrolidone $(\mathrm{Mw}=1,300,000)$ was fully dissolved into $30 \mathrm{~mL}$ mingled solution contained deionized water (DI) and ethylene glycol under the magnetic stirring for $1 \mathrm{~h}$ at $30^{\circ} \mathrm{C}$ until the solution became identical, and then ammonia solution was added till $\mathrm{PH}=9$. The uniform solution got after the magnetic stirring for 1 hour. Then solution trans- 
ferred to Teflon-lined stainless-steel autoclave, and then heated in a stove at $180^{\circ} \mathrm{C}$ for $20 \mathrm{~h}$, and Cooled down to room temperature normally. Next, the Precipitates by centrifugation were washed four times with ethanol and (DI), one by one, next, the sample dried up at $60^{\circ} \mathrm{C}$ for $24 \mathrm{~h}$. lastly, $\mathrm{SnO}_{2}$ flower-shaped were obtained through annealing process in a furnace at $400^{\circ} \mathrm{C}$ for $2 \mathrm{~h}$ at a ramping rate of $10^{\circ} \mathrm{C} / \mathrm{min}$.

Morphological analysis was carried out by Field-emission scanning electron microscopy (SEM, S-4800) and transmission electron microscopy (TEM, USA FEI TEVNAI G2 TF20). The specific surface area was analyzed by Brunauer-Emmett-Teller (BET) method through nitrogen adsorption using the BK132F instrument. The crystalline structure of $\mathrm{SnO}_{2}$ flower-shaped was determined by $\mathrm{X}$-ray diffraction (XRD, D/Max-2400) using $\mathrm{Cu} \mathrm{K} \alpha 1$ radiation with $\lambda=1.5406$ $\AA$, X-ray Photoelectron Spectroscopy (XPS, ESLALAB 220-XL) were examined the elemental composition and chemical state of $\mathrm{SnO}_{2}$ flower-shaped.

We tested the properties of the gas-sensing using a WS-30A gas sensing measurement system (Wei Sheng Electronics Science and Technology Co., Ltd., Henan Province, China).

The response value (R) was defined as $R_{a} / R_{g}$, where $R_{a}$ and $R_{g}$ were the resistance of the sensor in the air and in the test gas, respectively [18] [19]. The response and recovery times are defined as the time required to reach $90 \%$ of the final equilibrium value [20] [21].

We put a little of the powder obtained after calcination the process on a glass slide and mixed it with DI water to form clay, next, the slurry uniformly pasted with a toothpick onto a ceramic tube surface. Finally, the sensor was dried naturally at $24 \mathrm{~h}$ and was antiquated for $72 \mathrm{~h}$ to improve the stability [22], $\mathrm{Ni}-\mathrm{Cr}$ heating wire played a vital role to adjust the operating temperature (Figure 1(a)).

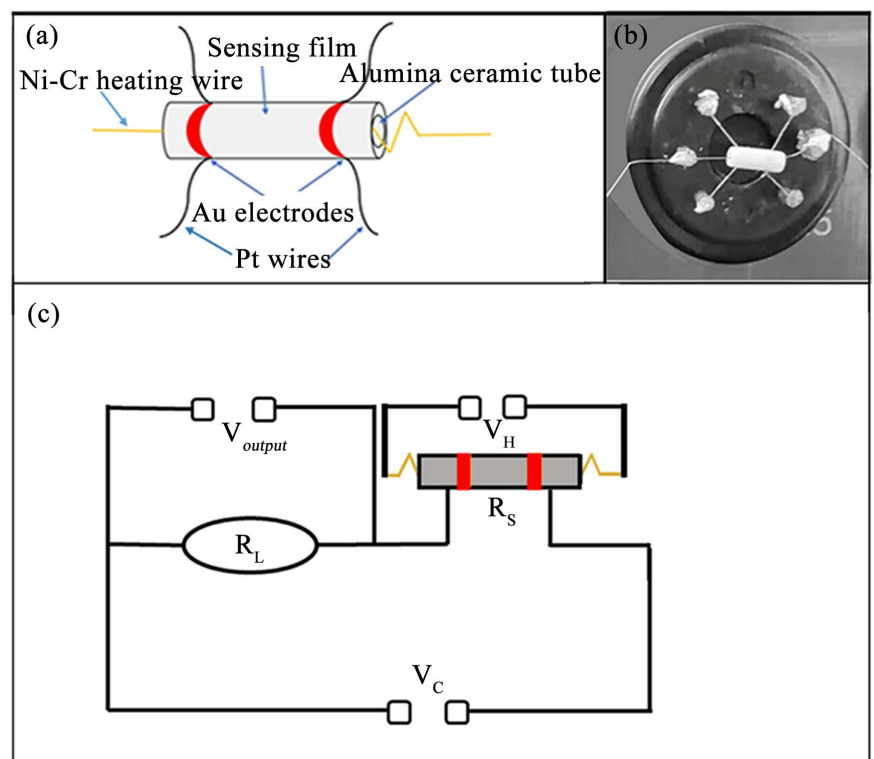

Figure 1. Graphic explanation of gas sensing device, ((a), (b)) the gas sensor and (c) the electrical circuit for gas sensing device. 
Figure $1(\mathrm{c})$ showed that load resistor $\left(\mathrm{R}_{\mathrm{L}}\right)$ and ready sensor have been tuned and were connected with $\mathrm{DC}$ power at $5 \mathrm{~V}$ in a gas sensing device. Then, it was selected $\left(\mathrm{R}_{\mathrm{L}}\right)$ and tuning by $\left(\mathrm{V}_{\mathrm{H}}\right)$ and was controlled the temperature of the Ni-Cr wire, in Figure 1(b), After inserting the sensor into the test room, the liquid was sprayed into the chamber (with $18 \mathrm{~L}$ volume) by the syringe according to the target gas concentrations, and there are also two fans for easy gas dispersion in the test room.

\section{Results and Discussion}

Figure 2 shows XRD patterns of $\mathrm{SnO}_{2}$ flower-shaped, it matches well all the diffraction peaks to the tetragonal rutile $\mathrm{SnO}_{2}$, which were indexed by the standard card (JCPDS, 41-1445) with $\mathrm{a}=\mathrm{b}=4.736 \AA$ and $\mathrm{c}=3.185 \AA$. That denotes a high crystallinity of the sample after calcining at $500^{\circ} \mathrm{C}$ for $3 \mathrm{~h}$. further, there is no impurity phase showed which indicates the prepared $\mathrm{SnO}_{2}$ was in high purity.

The nanosheets are become gathered and uniform by helping of PVP (Figure 3(a)), all the flower-shaped collected look like similar nanosheets with diameters of about $1 \mu \mathrm{m}$. Figure 3(b) showed that our sample is 3D nanostructures. Figure $3(c)$ and Figure 3(d) presented TEM images, the diameter of flower-shaped microstructures is $4 \mu \mathrm{m}$, and it is matching with SEM results. Besides, the rim portion of the flower-shaped structures is very clear because of the unique structures of nanosheets, Also uniform nanosheets are rough, which it's good for desorption and adsorption of gas molecules, subsequently, gas sensing improvement [23].

Meanwhile, the HRTEM image shown in Figure 3(e) the lattice distances of $\mathrm{SnO}_{2}$ flower-shaped are $0.232 \mathrm{~nm}$ and $0.267 \mathrm{~nm}$, it matched well with (200) (101) crystallographic orientation.

What's more, the inner figure in Figure 3(e) is the SAED pattern detected polycrystalline $\mathrm{SnO}_{2}$ nanostructures.

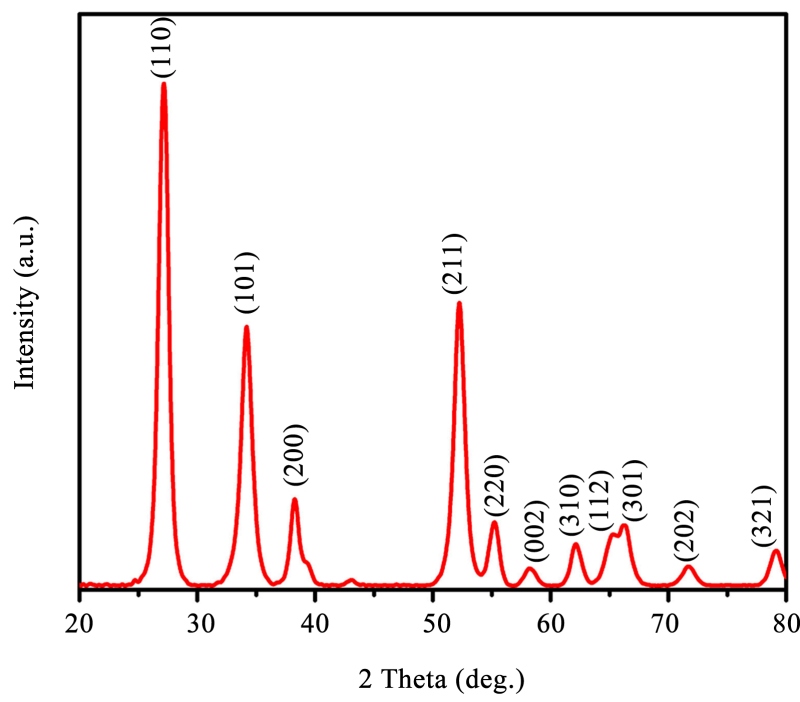

Figure 2. The XRD pattern of $\mathrm{SnO}_{2}$ flower-shaped. 


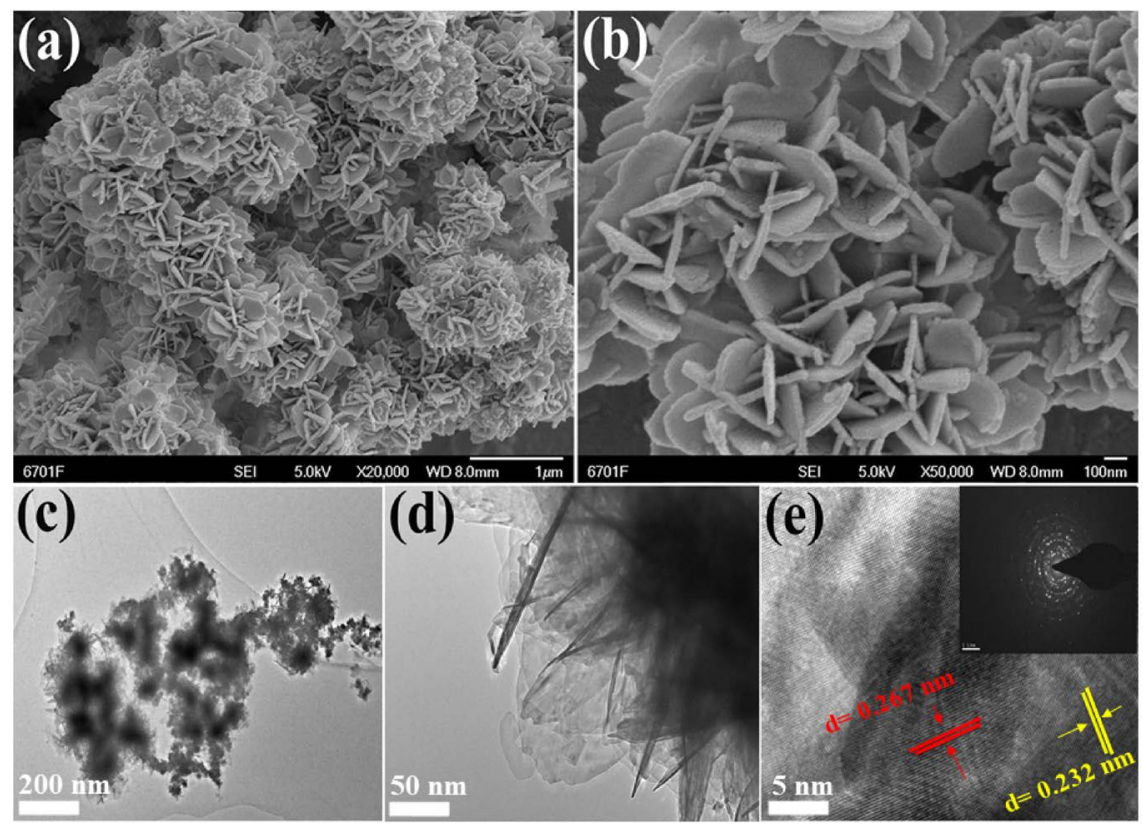

Figure 3. The morphologies of $\mathrm{SnO}_{2}$ flower-shaped: (a) The low enlargement SEM picture of $\mathrm{SnO}_{2}$ flower-shaped; and (b) The high enlargement SEM picture of $\mathrm{SnO}_{2}$ flower-shaped; ((c), (d)) The TEM picture of $\mathrm{SnO}_{2}$ flower-shaped; (e) The HRTEM picture of $\mathrm{SnO}_{2}$ flower-shaped, the inner figure in Figure 3(e) is SAED pattern.

Figure 4(a) displayed $\mathrm{N}$ desorption-adsorption of $\mathrm{SnO}_{2}$ sample, the $\mathrm{BJH}$ pore size is $30 \mathrm{~nm}$ and the surface area (BET) of $\mathrm{SnO}_{2}$ sample is $23.53 \mathrm{~m}^{2} / \mathrm{g}$. Generally, a great pore size is useful to gas disperse, also, a great surface area to supply more active sites, so this leads to improving gas sensing capability [24] [25]. Figures 4(b)-(d) presented XPS of $\mathrm{SnO}_{2}$ for the purpose of examining the elements and their corresponding valence state. The XPS broad spectrum showed the peaks of Sn, O, and C elements in the sample suggesting Sn has successfully co-operated toward the $\mathrm{SnO}_{2}$.

In Figure 4(c), the binding energies of Sn 3d established to 495.2 and 486.7 $\mathrm{eV}$ peaks and are compatible with $\mathrm{Sn} 3 \mathrm{~d}_{5 / 2}$ and $\mathrm{Sn} 3 \mathrm{~d}_{3 / 2}$ binding energies, respectively that is pointed out typical oxidation valence phase of $\mathrm{Sn}^{4+}$ [26] (Figure 4(d)). The binding energies of $\mathrm{O} 1 \mathrm{~s}$ separated at $530.6 \mathrm{eV}, 531.8$ peaks. And matched well to crystal lattice oxygen and adsorption oxygen, respectively [27], when the optimal operating temperature increasing, in Figure 5(a), the response of the gas sensor increases gradually until getting to the max value of 30 at $220^{\circ} \mathrm{C}$ and then decrease, and were calculated to $100 \mathrm{ppm} \mathrm{HCHO}$, this incident could be simply explained by the kinetics and thermodynamics of gas adsorption and desorption on the surface of the sensing layer [28] [29] from Figure 5(a), the optimal operating temperature of the sample is $220^{\circ} \mathrm{C}$ Also. As long as, in Figure 5(b), the response of the gas sensors application was very significant, and it was measured with different concentrations of formaldehyde $(5,15,25,50,100,150$, 200, 500 and $1000 \mathrm{ppm}$ ), when the formaldehyde concentration increases that means the response gradually going to increase the gas sensor almost be 


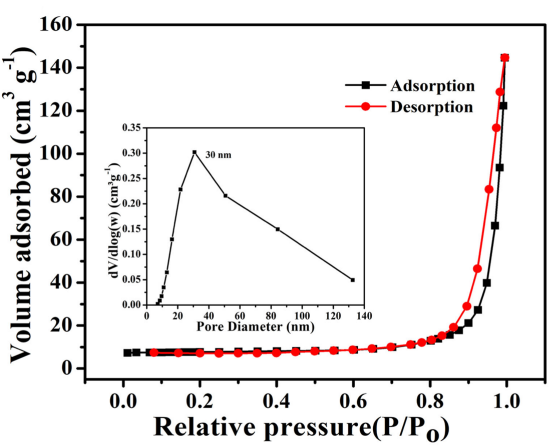

(a)

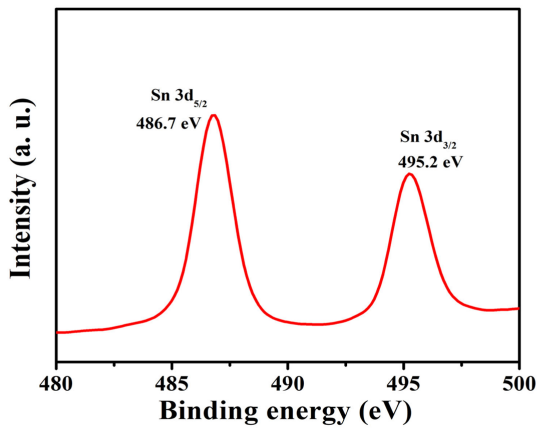

(c)

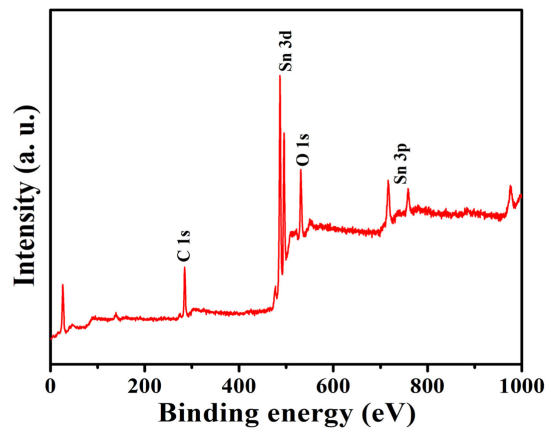

(b)

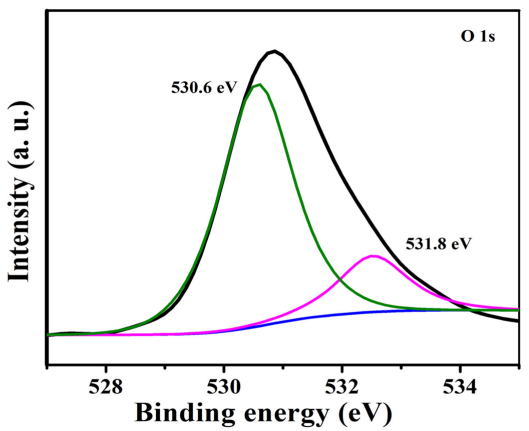

(d)

Figure 4. (a) $\mathrm{N}_{2}$ desorption-adsorption of $\mathrm{SnO}_{2}$ flower-shaped and the inner figure is pore-size distribution curves obtained by $\mathrm{BJH}$ method, XPS spectra of the $\mathrm{SnO}_{2}$; (b) a survey spectrum; (c) Sn 3d; (d) O 1s.

stable when the concentration is above $200 \mathrm{ppm}$, which means It connects the responses with the low concentrations. The dynamic response/recovery times of (3D) $\mathrm{SnO}_{2}$ flower-shaped exhibited in Figure 5(c) for different concentrations $(15,25,50,100$, and 200$) \mathrm{ppm}$ at $220^{\circ} \mathrm{C}$ for $\mathrm{HCHO}$, we can obviously see that the response increases gradually with an increasing concentration of HCHO. This shows that our sensor can show a significant response (about 7 for Formaldehyde), while the gas concentration is low (15 ppm). That leads to sensing properties of the sample (3D) $\mathrm{SnO}_{2}$ flower-shaped is good. Figure 5(d) the response/recovery times to $50 \mathrm{ppm}$ formaldehyde about $5 \mathrm{~s}$ and $22 \mathrm{~s}$ respectively. The rough surface has a significant role in short recovery and response times. the selectivity of the sample is a necessary role for the performance of gas sensing, the selectivity of the sample was examined to different gasses in Figure 5(e) displayed Our sensor is high selectivity to formaldehyde, Figure $5(\mathrm{f})$ we have tested the stability of the sample in a few days, which clarified that our sample is gradually stable. Also, Table 1 summarized comparison between this work and previous works reported.

The mechanism of the $\mathrm{SnO}_{2}$ sample was also investigated in Figure 6. (Ammonia, Polyvinylpyrrolidone and sodium citrate) are a key factor affecting the morphology growth in good shape, the $\mathrm{NH}_{3} \cdot \mathrm{H}_{2} \mathrm{O}$ can release $\mathrm{OH}^{-}$as a low alkaline solution that reacts with $\mathrm{Sn}^{2+}$, thus its control the final $\mathrm{SnO}_{2}$ flower-shaped [35]. In the next equations, we explain that: 


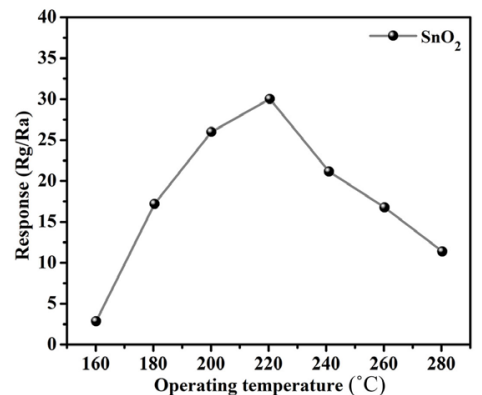

(a)

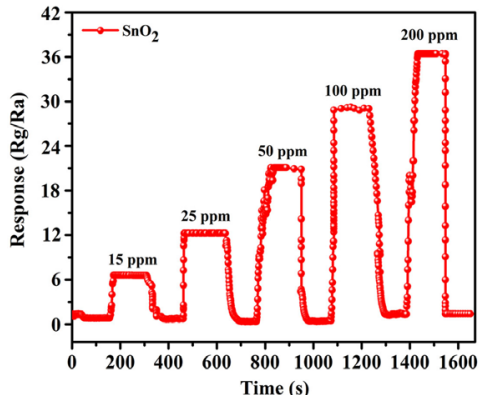

(c)

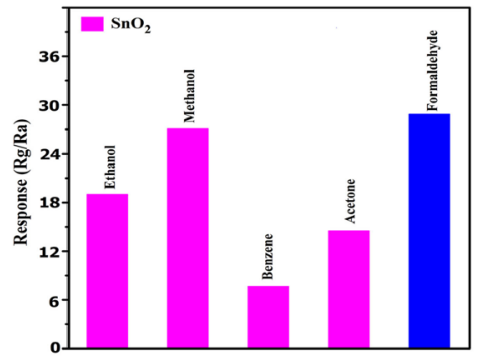

(e)

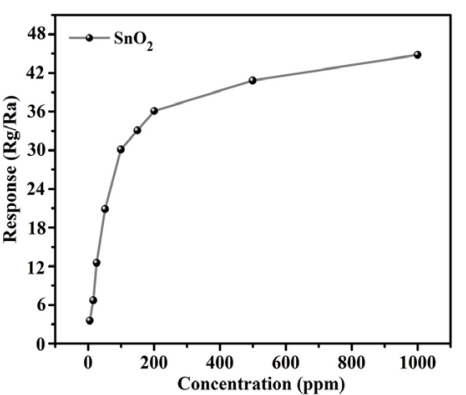

(b)

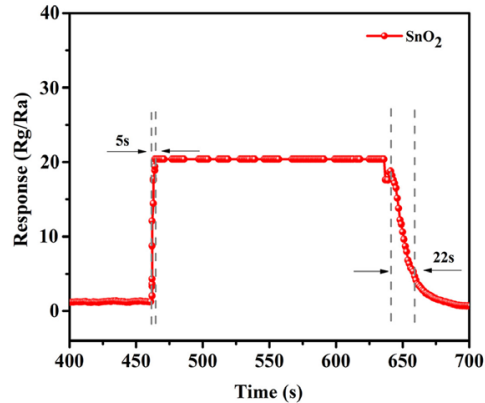

(d)

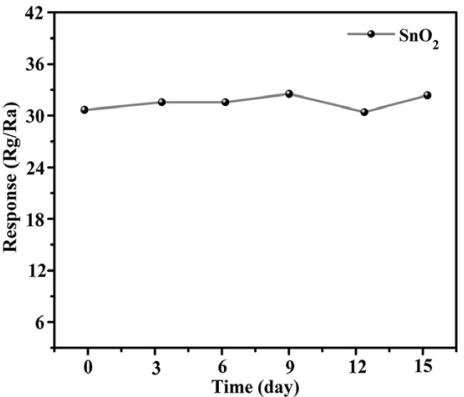

(f)

Figure 5. (a) gas sensor responses of sample to $100 \mathrm{ppm} \mathrm{HCHO}$ to different operating temperatures; (b) gas sensor responses to different concentrations (5 - $1000 \mathrm{ppm}$ ) of $\mathrm{HCHO}$; (c) The response/recovery time to 15, 25, 50, 100, 200, ppm HCHO; (d) the response and recover time towards $50 \mathrm{ppm} \mathrm{HCHO}$ at $220^{\circ} \mathrm{C}$; (e) The responses of $\mathrm{SnO}_{2}$ sample to $100 \mathrm{ppm}$ various test gases; (f) The stability of $\mathrm{SnO}_{2}$ sample to $100 \mathrm{ppm} \mathrm{HCHO}$ at $220^{\circ} \mathrm{C}$.

Table 1. Showed a comparison of various $\mathrm{SnO}_{2}$ sensors between published work and this work.

\begin{tabular}{cccccc}
\hline Sensor materials & $\begin{array}{c}\text { Con } \\
(\mathrm{ppm})\end{array}$ & Selectivity & $\begin{array}{c}\text { Gas } \\
\text { response }\end{array}$ & $\begin{array}{c}\text { Synthetic } \\
\text { method }\end{array}$ & Ref. \\
\hline Porous $\mathrm{SnO}_{2}$ nanowires & 100 & ethanol & $\sim 1.7$ & $\mathrm{EF}, \mathrm{HM}$ & {$[30]$} \\
$\mathrm{GO} / \mathrm{SnO}_{2}$ nanosheets & 100 & ethanol & 2.9 & $\mathrm{HM}$ & {$[31]$} \\
$\mathrm{WO}_{3}-\mathrm{SnO}_{2}$ nanosphere & 1000 & acetone & 16.9 & $\mathrm{HM}$ & {$[32]$} \\
La-doped $\mathrm{SnO}_{2}$ nanoparticles & 5 & formaldehyde & 4.2 & $\mathrm{BM}$ & {$[33]$} \\
Porous flower-like $\mathrm{SnO}_{2}$ & 100 & $\begin{array}{c}\text { formaldehyde, } \\
\text { ethanol }\end{array}$ & 24.8 & $\mathrm{HM}$ & {$[34]$} \\
$\mathrm{SnO}_{2}$ flower-shaped & 100 & formaldehyde & 30.0 & $\mathrm{HM}$ & this work \\
\hline
\end{tabular}

Where: $\mathrm{EF}=$ electrospinning followed, $\mathrm{HM}=$ hydrothermal method, $\mathrm{BM}=$ Ball-milling solid chemical reaction method. 


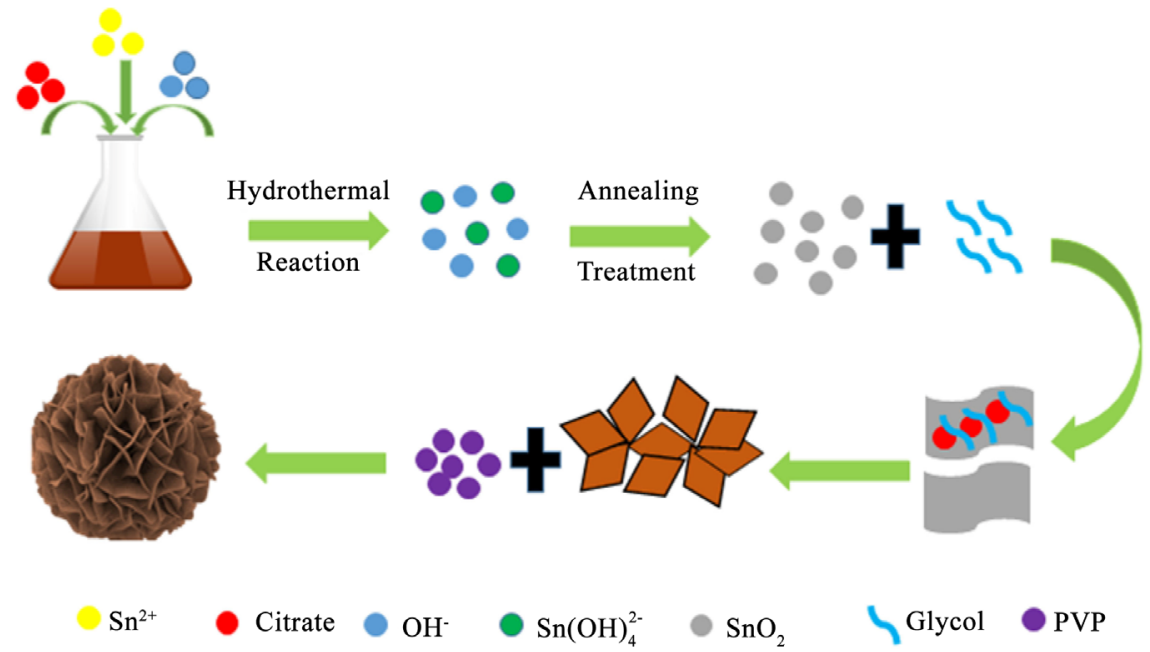

Figure 6. Gas sensing mechanism of $\mathrm{SnO}_{2}$ flower-shaped.

$$
\begin{gathered}
\mathrm{NH}_{3} \cdot \mathrm{H}_{2} \mathrm{O} \rightarrow \mathrm{NH}_{4}^{+}+\mathrm{OH}^{-} \\
\mathrm{Sn}^{2+}+4 \mathrm{OH}^{-} \rightarrow \mathrm{Sn}(\mathrm{OH})_{4}^{2-} \\
\mathrm{Sn}(\mathrm{OH})_{4}^{2-} \rightarrow \mathrm{SnO}_{2}+2 \mathrm{H}_{2} \mathrm{O}+2 \mathrm{e}^{-}
\end{gathered}
$$

While the nanosheets increase more separately, individually and uniformly due to PVP, the growth of $\mathrm{SnO}_{2}$ nanosheets and accelerate the gathering of nanosheets into flower-shaped by sodium citrate [36].

\section{Conclusion}

The pure $\mathrm{SnO}_{2}$ flower-shaped was fabricated through the hydrothermal method, the sensor has good sensitivity, stability, high response (30 s), and excellent selectivity to formaldehyde at $220^{\circ} \mathrm{C}$, and a high response/recovery time about (5 s and $22 \mathrm{~s}$ ). Also, the mechanism of $\mathrm{SnO}_{2}$ gas sensors is also discussed. Thus, the $\mathrm{SnO}_{2}$ could become a promising gas sensing material to formaldehyde.

\section{Acknowledgements}

This work was supported by the National Natural Science Foundation of China (Grant No. 11864034 and 11964035), and the Scientific Research Project of Gansu Province (Grant No. 18JR3RA089 and 17JR5RA072).

\section{Conflicts of Interest}

The authors declare that they have no known competing financial interests or personal relationships that could have appeared to influence the work reported in this paper.

\section{References}

[1] Pei, S., Ma, S., Xu, X., Xu, X. and Almamoun. O. (2021) Modulated $\mathrm{PrFeO}_{3}$ by Doping $\mathrm{Sm}^{3+}$ for Enhanced Acetone Sensing Properties. Journal of Alloys and 
Compounds, 856, Article ID: 158274. https://doi.org/10.1016/j.jallcom.2020.158274

[2] Yang, T.T., Ma, S.Y., Cao, P.F., Xu, X.L., Wang, L., Pei, S.T., et al. (2021) Synthesis

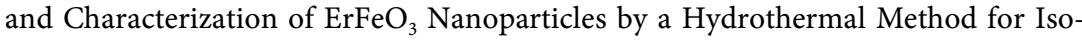
propanol Sensing Properties. Vacuum, 185, Article ID: 110005.

https://doi.org/10.1016/j.vacuum.2020.110005

[3] Tie, Y., Ma, S.Y., Pei, S.T., Zhang, Q.X., Zhu, K.M., Zhang, R., et al. (2020) Pr Doped $\mathrm{BiFeO}_{3}$ Hollow Nano Fibers via Electrospinning Method as a Formaldehyde Sensor. Sensors and Actuators B: Chemical, 308, Article ID: 127689. https://doi.org/10.1016/j.snb.2020.127689

[4] Zhang, G.H., Chen, Q., Deng, X.Y., Jiao, H.Y., Wang, P.Y. and Gengzang, D.J. (2019) Synthesis and Characterization of In-Doped $\mathrm{LaFeO}_{3}$ Hollow Nanofibers with Enhanced Formaldehyde Sensing Properties. Materials Letters, 236, 229-232. https://doi.org/10.1016/j.matlet.2018.10.062

[5] Zhang, R., Ma, S.Y., Zhang, Q.X., Zhu, K.M., Tie, Y., Pei, S.T., et al. (2019) Highly Sensitive Formaldehyde Gas Sensors Based on Ag Doped $\mathrm{Zn}_{2} \mathrm{SnO}_{4} / \mathrm{SnO}_{2}$ Hollow Nanospheres. Materials Letters, 254, 178-181.

https://doi.org/10.1016/j.matlet.2019.07.065

[6] Zhu, K.M., Ma, S.Y., Pei, S.T., Tie, Y., Zhang, Q.X., Wang, W.Q., et al. (2019) Preparation, Characterization and Formaldehyde Gas Sensing Properties of Walnut-shaped $\mathrm{BiFeO}_{3}$ Microspheres. Materials Letters, 246, 107-110. https://doi.org/10.1016/j.matlet.2019.02.129

[7] Fu, X., Yang, P., Xiao, X., Zhou, D., Huang, R., Zhang, X., et al. (2019) Ultra-Fast and Highly Selective Room-Temperature Formaldehyde Gas Sensing of Pt-Decorated $\mathrm{MoO}_{3}$ Nanobelts. Journal of Alloys and Compounds, 797, 666-675.

https://doi.org/10.1016/j.jallcom.2019.05.145

[8] Liu, F., Chen, X., Wang, X., Han, Y., Song, X., Tian, J., et al. (2019) Fabrication of $1 \mathrm{D} \mathrm{Zn}_{2} \mathrm{SnO}_{4}$ Nanowire and 2D ZnO Nanosheet Hybrid Hierarchical Structures for Use in Triethylamine Gas Sensors. Sensors and Actuators B: Chemical, 291, 155-163. https://doi.org/10.1016/j.snb.2019.04.009

[9] Xue, D., Zhang, Z. and Wang, Y. (2019) Enhanced Methane Sensing Performance of $\mathrm{SnO}_{2}$ Nanoflowers Based Sensors Decorated with $\mathrm{Au}$ Nanoparticles. Materials Chemistry and Physics, 237, Article ID: 121864. https://doi.org/10.1016/j.matchemphys.2019.121864

[10] Wang, X., Liu, F., Chen, X., Lu, G., Song, X., Tian, J., et al. (2020) $\mathrm{SnO}_{2}$ Core-Shell Hollow Microspheres Co-Modification with $\mathrm{Au}$ and $\mathrm{NiO}$ Nanoparticles for Acetone Gas Sensing. Powder Technology, 364, 159-166. https://doi.org/10.1016/j.powtec.2020.02.006

[11] Xue, D., Wang, Y., Cao, J., Sun, G. and Zhang, Z. (2019) Improving Methane Gas Sensing Performance of Flower-Like $\mathrm{SnO}_{2}$ Decorated by $\mathrm{WO}_{3}$ Nanoplates. Talanta, 199, 603-611. https://doi.org/10.1016/j.talanta.2019.03.014

[12] Wei, Q., Song, P., Li, Z., Yang, Z. and Wang, Q. (2017) Hierarchical Peony-Like Sb-Doped $\mathrm{SnO}_{2}$ Nanostructures: Synthesis, Characterization and HCHO Sensing Properties. Materials Letters, 191, 173-177.

https://doi.org/10.1016/j.matlet.2016.12.070

[13] Cao, J., Qin, C., Wang, Y., Zhang, H., Zhang, B., Gong, Y., et al. (2017) Synthesis of G- $\mathrm{C}_{3} \mathrm{~N}_{4}$ Nanosheet Modified $\mathrm{SnO}_{2}$ Composites with Improved Performance for Ethanol Gas Sensing. RSC Advances, 7, 25504-25511. https://doi.org/10.1039/C7RA01901G

[14] Chen, W.C., Foxley, S. and Miller, K.L. (2013) Detecting Microstructural Properties 
of White Matter Based on Compartmentalization of Magnetic Susceptibility. NeuroImage, 70, 1-9. https://doi.org/10.1016/j.neuroimage.2012.12.032

[15] Kim, K.M., Choi, K.I, Jeong, H.M., Kim, H.J., Kim, H.R. and Lee, J.H. (2012) Highly Sensitive and Selective Trimethylamine Sensors Using Ru-Doped $\mathrm{SnO}_{2}$ Hollow Spheres. Sensors and Actuators B: Chemical, 166-167, 733-738.

https://doi.org/10.1016/j.snb.2012.03.049

[16] Wang, D., Chu, X. and Gong, M. (2006) Gas-Sensing Properties of Sensors Based on Single-Crystalline $\mathrm{SnO}_{2}$ Nanorods Prepared by a Simple Molten-Salt Method. Sensors and Actuators B: Chemical, 117, 183-187.

https://doi.org/10.1016/j.snb.2005.11.022

[17] Hoefer, U., Frank, J. and Fleischer, M. (2001) High Temperature Ga2O3-Gas Sensors and $\mathrm{SnO}_{2}$-Gas Sensors: A Comparison. Sensors and Actuators B: Chemical, 78, 6-11. https://doi.org/10.1016/S0925-4005(01)00784-5

[18] Ma, L., Ma, S.Y., Shen, X.F., Wang, T.T., Jiang, X.H., Chen, Q., et al. (2018) $\mathrm{PrFeO}_{3}$ Hollow Nanofibers as a Highly Efficient Gas Sensor for Acetone Detection. Sensors and Actuators B: Chemical, 255, 2546-2554.

https://doi.org/10.1016/j.snb.2017.09.060

[19] Chen, Q., Ma, S.Y., Xu, X.L., Jiao, H.Y., Zhang, G.H., Liu, L.W., et al. (2018) Optimization Ethanol Detection Performance Manifested by Gas Sensor Based on $\mathrm{In}_{2} \mathrm{O}_{3} / \mathrm{ZnS}$ Rough Microspheres. Sensors and Actuators B: Chemical, 264, 263-278. https://doi.org/10.1016/j.snb.2018.02.172

[20] Cao, P.F., Ma, S.Y., Xu, X.L., Wang, B.J., Almamoun, O., Han, T., et al. (2020) Preparation and Characterization of a Novel Ethanol Gas Sensor Based on $\mathrm{FeYO}_{3}$ Microspheres by Using Orange Peels as Bio-Templates. Vacuum, 177, Article ID: 109359. https://doi.org/10.1016/j.vacuum.2020.109359

[21] Lu, J., Liang, K., Xu, C., Wang, X., Ouyang, H., Huang, J., et al. (2019) Humidity Sensor Based on heterogeneous $\mathrm{CoTiO}_{3} / \mathrm{TiO}_{2}$ Film with Vertically Aligned Nanocrystalline Structure. Vacuum, 163, 292-300.

https://doi.org/10.1016/j.vacuum.2019.02.027

[22] Kapse ,V.D., Ghosh, S.A., Chaudhari, G.N., Raghuwanshi, F.C. and Gulwade, D.D. (2008) H2S Sensing Properties of La-Doped Nanocrystalline $\operatorname{In}_{2} \mathrm{O}_{3}$. Vacuum, 83, 346-352. https://doi.org/10.1016/j.vacuum.2008.05.027

[23] Jin, W.X., Ma, S.Y., Tie, Z.Z., Wei, J.J., Luo, J., Jiang, X.H., et al. (2015) One-Step Synthesis and Highly Gas-Sensing Properties of Hierarchical Cu-Doped $\mathrm{SnO}_{2} \mathrm{Na}-$ noflowers. Sensors and Actuators B: Chemical, 213, 171-180. https://doi.org/10.1016/j.snb.2015.02.075

[24] Li, J., Fan, H. and Jia, X. (2010) Multilayered ZnO Nanosheets with 3D Porous Architectures: Synthesis and Gas Sensing Application. The Journal of Physical Chemistry C, 114, 14684-14691. https://doi.org/10.1021/jp100792c

[25] Yang, D. and Liu, Z. (2007) One-Dimensional Nanostructures of Silicon: Synthesis, Characterization and Applications. ChemInform, 39, 95-110.

[26] Ge, H., Wang, C. and Yin, L. (2015) Hierarchical $\mathrm{Cu}_{0.27} \mathrm{Co}_{2.73} \mathrm{O}_{4} / \mathrm{MnO}_{2}$ Nanorod Arrays Grown on 3D Nickel Foam as Promising Electrode Materials for Electrochemical Capacitors. Journal of Materials Chemistry A, 3, 17359-17368. https://doi.org/10.1039/C5TA03049H

[27] Zhang, R., Xu, Z., Zhou, T., Fei, T., Wang, R. and Zhang, T. (2019) Improvement of Gas Sensing Performance for Tin Dioxide Sensor through Construction of Nanostructures. Journal of Colloid and Interface Science, 557, 673-682. https://doi.org/10.1016/j.jcis.2019.09.073 
[28] Cao, J., Zhang, H. and Yan, X. (2016) Facile Fabrication and Enhanced Formaldehyde Gas Sensing Properties of Nanoparticles-Assembled Chain-Like NiO Architectures. Materials Letters, 185, 40-42. https://doi.org/10.1016/j.matlet.2016.08.099

[29] Wei, Q., Sun, J., Song, P., Li, J., Yang, Z. and Wang, Q. (2020) MOF-Derived $\alpha-\mathrm{Fe}_{2} \mathrm{O}_{3}$ Porous Spindle Combined with Reduced Graphene Oxide for Improvement of TEA Sensing Performance. Sensors and Actuators B: Chemical, 304, Article ID: 127306. https://doi.org/10.1016/j.snb.2019.127306

[30] Li, R., Chen, S., Lou, Z., Li, L., Huang, T., Song, Y., et al. (2017) Fabrication of Porous $\mathrm{SnO}_{2}$ Nanowires Gas Sensors with Enhanced Sensitivity. Sensors and Actuators B: Chemical, 252, 79-85. https://doi.org/10.1016/j.snb.2017.05.161

[31] Zhao, C., Gong, H., Lan, W., Ramachandran, R., Xu, H., Liu, S., et al. (2018) Facile Synthesis of $\mathrm{SnO} 2$ Hierarchical Porous Nanosheets from Graphene Oxide Sacrificial Scaffolds for high-Performance Gas Sensors. Sensors and Actuators B: Chemical, 258, 492-500. https://doi.org/10.1016/j.snb.2017.11.167

[32] Zhu, Y., Wang, H., Liu, J., Yin, M., Yu, L., Zhou, J., et al. (2019) High-Performance Gas Sensors Based on the $\mathrm{WO}_{3}-\mathrm{SnO}_{2}$ Nanosphere Composites. Journal of Alloys and Compounds, 782, 789-795. https://doi.org/10.1016/j.jallcom.2018.12.178

[33] Xiang, X., Zhu, D. and Wang, D. (2016) Enhanced Formaldehyde Gas Sensing Properties of La-Doped $\mathrm{SnO}_{2}$ Nanoparticles Prepared by Ball-Milling Solid Chemical Reaction Method. Journal of Materials Science: Materials in Electronics, 27, 7425-7432. https://doi.org/10.1007/s10854-016-4718-8

[34] Ren, H., Zhao, W., Wang, L., Ryu, S.O. and Gu, C. (2015) Preparation of Porous Flower-Like $\mathrm{SnO}_{2}$ Micro/Nano Structures and Their Enhanced Gas Sensing Property. Journal of Alloys and Compounds, 653, 611-618. https://doi.org/10.1016/j.jallcom.2015.09.065

[35] Suwanboon, S., Amornpitoksuk, P. and Muensit, N. (2011) Dependence of Photocatalytic Activity on Structural and Optical Properties of Nanocrystalline $\mathrm{ZnO}$ Powders. Ceramics International, 37, 2247-2253. https://doi.org/10.1016/j.ceramint.2011.03.016

[36] Luo, J., Ma, S.Y., Li, F.M., Li, X.B., Li, W.Q., Cheng, L., et al. (2014) The Mesoscopic Structure of Flower-Like ZnO Nanorods for Acetone Detection. Materials Letters, 121, 137-140. https://doi.org/10.1016/j.matlet.2014.01.155 